\title{
ERRATUM
}

\section{Erratum to: A novel anchoring system for colonic stents: a pilot in vivo study in a porcine model}

\author{
A. Nevler $\cdot$ U. Willantz $\cdot$ O. Doron · \\ J. Sandbank $\cdot$ Y. Ziv
}

Published online: 6 February 2014

(C) Springer-Verlag Italia 2014

\section{Erratum to: Tech Coloproctol}

\section{DOI 10.1007/s10151-013-1097-5}

The manuscript supplied for publication contained an incomplete affiliation for the first author, Dr. Avinoam Nevler. The full affiliation is as follows:
A. Nevler
The Dr. Pinchas Borenstein Talpiot Medical Leadership Program 2012, Department of Surgery and Transplantation, Chaim Sheba Medical Center, 52621 Tel-Hashomer, Israel.

The online version of the original article can be found under doi:10.1007/s10151-013-1097-5.

\footnotetext{
A. Nevler

The Dr. Pinchas Borenstein Talpiot Medical Leadership Program

2012, Department of Surgery and Transplantation, Chaim Sheba

Medical Center, 52621 Tel-Hashomer, Israel

U. Willantz · O. Doron

Lahav Research Institute, Kibbutz Lahav, Israel

J. Sandbank

Department of Pathology, Assaf Harofeh Medical Center,

Zerifin, Israel

Y. Ziv $(\bowtie)$

Coloproctology Unit, Division of Surgery, Assaf Harofeh

Medical Center, 70300 Zerifin, Israel

e-mail: dryziv@gmail.com
} 